\title{
EDS Postgraduate Course in Chronic Pancreatitis
}

\author{
Bergen, Norway, May 27-28,1999
}

\section{Main Topics}

- Chronic pancreatitis 1999: what are the issues?

- Molecular aspects on etiology of chronic pancreatitis

- The ras-story

- Bleeding complications due to chronic pancreatitis

- Pancreas divisum

- Longacting somatostatine analogue as treatment of chronic pancreatitis

- Medical treatment of pancreatic insufficiency

\section{Faculty}

H. Beger, UIm

M. Cremer, Brussels

J. Emmerich, Rostock

L. Fernandez-Cruz, Barcelona

G. Flati, Rome

P. Layer, Hamburg
M. Löhr, Rostock

C. Russel, London

M. Schönberg,

München

P. Toskes, Gainsville

W. Traverso, Seattle

G. Tsiotos, Kansas City
- Endoscopic treatment of complications to chronic pancreatitis

- Drainage of the pancreatic duct or resect?

- Experiences with pylorus-preserving pancreatic head resection in chronic pancreatitis

- Experiences with duodenum-preserving head resection in chronic pancreatitis

- Complications to surgery in chronic pancreatitis

\section{Congress Information}

Chairman: Ake Andrén-Sanberg

Department of Surgery

Haukeland University Hospital

$\mathrm{N}-5021$ Bergen

Norway

Tel. +47 55972755

Fax +47 55972793 